\title{
Platelet rich plasma injection for achilles tendinopathy
}

\author{
Luke Sammut* \\ Rheumatology Department, University Hospital Southampton, NHS Foundation Trust, UK
}

\begin{abstract}
Introduction: Our increasing knowledge, understanding and preliminary evidence from experimental data that growth factors, present in platelets, boost the tendon repair mechanisms through recruitment, proliferation and differentiation of cells, has driven the use of Platelet-rich plasma (PRP) preparations in the treatment of Achilles tendinopathy.

Objective: To report outcomes and clinical efficacy of PRP as a treatment for Achilles tendinopathy.

Methods: A comprehensive, systematic literature review.

Results: Four Studies involving 110 tendons were included after screening; one Randomised controlled trial (RCT) and three observational non controlled trials. In the only available RCT, the mean VISA-A score improved significantly within the PRP. However once adjusted for baseline VISA scores and duration of symptoms, there was no difference between the treatment groups. The other non-controlled studies reported promising results with improvement in outcome measures, with one of the studies reporting a significant improvement in imaging results in 27 out of 29 subjects.
\end{abstract}

Conclusions: The clinically applicable evidence on the role of PRP in Achilles tendinopathy to date stems mainly from the above four studies. While these early findings are clearly of considerable interest to the athletes and the clinical population, longer term well-conducted studies, are needed.

\begin{abstract}
Abbreviations: AOFAS: American Orthopaedic Foot \& Ankle Society; Bfgf: Basic Fibroblast Growth Factor; CI: Confidence Interval; CAM: Controlled Ankle Motion; EDGF1: Endothelial Cell Growth Factor; EGF: Epidermal Growth Factor, FAAMS: Foot and Ankle Ability Measure - Sports; FAAM: Foot and Ankle Ability Measure; GF: Growth Factors; IGF: Insulin-like Growth Factor; MRI: Magnetic resonance imaging; PRP: Platelet Rich Plasma; PDGF: Platelet Derived Growth Factor; PDUS: Power-Doppler ultrasonography; RCT: Randomised Controlled Trial; SF-8: Short Form health survey; SD: Standard Deviation; TGF- $\beta$ : Transforming Growth Factor Beta 1; US: Ultrasound; VEGF: Vascular Endothelial Growth Factor; VISA-A: Victorian Institute of Sport Assessment - Achilles.
\end{abstract}

\section{Introduction}

Achilles tendinopathy is a common condition affecting the Achilles tendon, characterised by pain, swelling, weakness and stiffness $[1,2]$. Its aetiology is likely to be multifactorial with repetitive exposure to trauma leading to tendon degeneration, microtears and impairment of tendon repair [1,3-8].

Although previously thought to be an inflammatory condition, clinical, imaging and histological examinations have shown that the process is predominantly degenerative with local disruption of the collagen matrix and microtears [5]. It is characterized by hypercellularity, fibroblast proliferation, and collagen disorganization [9] more commonly termed angiofibroblastic hyperplasia [10]. This has lead to the previous term of tendinitis to be discontinued for these lesions. The presence of erratic blood flow with chaotic zones of hypovascularization and hypervascularization also plays a role in the disease process [11]. These pathological processes most commonly develop at 2-6 cm above the insertion of the Achilles tendon (noninsertional tendinopathy) or the tendon attachment to the calcaneus (insertional tendinopathy) [12].
There is no agreement on the ideal treatment modality for Achilles tendinopathy and this remains a complex difficult challenge [13]. This has led to the introduction of a large number of conservative treatments including rest, immobilisation, analgesia, NSAIDs, orthotics, physiotherapy, local injections, extracorporeal shock wave therapy and topical glyceryl trinitrate $[10,14]$.

In an 8 -year follow-up study, $29 \%$ failed conservative treatment [15] and were surgically treated. Surgical treatments options that have been explored include operative debridement, autogenous flexor hallucis longus or flexor digitorum longus tendon transfer, and allograft augmentation [13].

\section{Platelets and growth factors}

Platelets play an active role in homeostasis during the initial inflammatory phases. Platelets become activated through the adhesion process, aggregation, clot formation, and release a range of mitogenic and strong inflammatory mediators into the local microenvironment [16].

Dense granules, alpha-granules and lysosomes release proteins, growth factors (GF), chemokines and coagulation factors. These substances act in a concerted and finely regulated manner to influence and promote tissue repair functions $[17,18]$. GF released from alpha granules are summarised in table $1[19,20,21]$. The majority of GF are secreted within the first hour of platelet degranulation and activation,

Correspondence to: L Sammut, Rheumatology Department, University Hospital Southampton, NHS Foundation Trust, Tremona Road, Southampton SO16 6YD, UK; E-mail: lukesammut@doctors.org.uk

Received: February 02, 2018; Accepted: February 13, 2018; Published: February 15,2018 
Table 1. Growth Factors present in Platelet Rich Plasma.

\begin{tabular}{|c|c|c|}
\hline Growth Factor & Abbreviation & Mechanism of Function \\
\hline Platelet Derived Growth Factor & PDGF & $\begin{array}{l}\text { Chemotaxis, cellular proliferation, } \\
\text { stimulates fibroblast production \& } \\
\text { angiogenesis }\end{array}$ \\
\hline $\begin{array}{l}\text { Transforming Growth Factor - } \\
\text { Beta } 1\end{array}$ & TGF- $\beta 1$ & $\begin{array}{l}\text { Promotes extracellular Matrix } \\
\text { Synthesis }\end{array}$ \\
\hline Epidermal Growth Factor & EGF & $\begin{array}{l}\text { Cellular Proliferation \& differentiation. } \\
\text { angiogenesis, proliferation of } \\
\text { mesenchymal and epithelial cells }\end{array}$ \\
\hline $\begin{array}{l}\text { Vascular Endothelial Growth } \\
\text { Factor }\end{array}$ & VEGF & Promotes angiogenesis \\
\hline Endothelial Cell Growth Factor & EDGF1 & $\begin{array}{l}\text { Endothelial cell proliferation, } \\
\text { angiogenesis }\end{array}$ \\
\hline Insulin-like Growth Factor & IGF & Stimulates fibroblasts and myoblasts \\
\hline Basic Fibroblast Growth Factor & bFGF & $\begin{array}{l}\text { Produces collagen; stimulates } \\
\text { angiogenesis, proliferation of } \\
\text { myoblasts }\end{array}$ \\
\hline
\end{tabular}

with continued release occurring throughout the seven day period of platelet viability [21].

By binding to specific receptors on cell surfaces, GF activate specific intracellular signalling molecules within the cell which may act independently or synergistically with other GF. This initiates a pathway cascade leading to transcription of specific regulatory genes, DNA synthesis and expression [22].

The GF are known to be important in the initiation and acceleration of tendon repair and regeneration, by stimulating the recruitment of fibroblasts, stem cells and inflammatory cells to the injury site, regulating cell migration, angiogenesis, stimulating synthesis of collagen and extracellular matrix [22,23].

The progression of our understanding of the processes that regulate tendon repair and the platelets' capacity to release a multitude of GF have led to the exploration of platelets as a delivery tool for GF in tendinopathy [11].

\section{Platelet rich plasma}

Platelet-rich plasma (PRP) is a sample of autologous blood with high concentrations of platelets and associated GF which may induce and accelerate tendon repair [14-17]. PRP is prepared from a $20-60 \mathrm{ml}$ sample of whole blood which is anticoagulated with $2-7 \mathrm{ml}$ of citrate dextrose to prevent premature platelet activation. After collection, the sample is then centrifuged in a two stage process to concentrate platelets in plasma to levels 7-10 times above baseline values. Its specific contents have not been clearly defined and standardised in the literature, with platelet concentrations differing between studies. Analysis of the GF levels in PRP have shown Platelet derived Growth Factor (PDGF) 25 times the baseline value while Epidermal Growth Factor (EGF), Transforming Growth Factor Beta 1 (TGF $\beta 1$ ), and Vascular Endothelial Growth Factor (VEGF) levels can rise to 10 times baseline (14). However there are variations in the concentrations of GF and platelet counts in PRP [29,30,31]. The diversity of PRP products and the PRP techniques should be taken into account when reviewing and analysing studies using PRP [16].

\section{Literature review \& analysis}

A comprehensive, systematic literature review was conducted using databases of PubMed, Google Scholar and the Cochrane library. The following search terms were used in differing combinations: 'tendinopathy', 'tendinosis', 'Achilles', 'tendon', 'PRP', 'platelet', 'autologous blood' or 'injection'. The literature was limited to human studies and adults and articles in English. The inclusion criteria are listed in figure 1. All titles and abstracts, without time limits, were reviewed and a total of 539 studies were initially obtained (Figure 2). Four Studies were included after screening; one Randomised controlled trial (RCT) [24], two prospective case series [12,13] and one retrospective study design [25]. These are described in detail in table 2.

\section{Methodological assessment}

The methodological quality of the studies was assessed using a modified Coleman Methodology Score (CMS). The CMS was originally developed for grading clinical studies in patellar and achilles tendinopathy. This scoring classification uses 10 criteria and a maximum score of 100 would represent a study design that avoids the different biases and confounding factors. The CMS was modified by excluding the category describing the number of different procedures because this review only included one type of procedure, the PRP injection. Our modified CMS included 9 criteria, giving a total CMS of between 0 and 90 , were 90 is the maximal score and indicates perfect study design.

The mean number of subjects included in the study was 27 (SD 19.9, range 10-54). In total, there were 53 Males and 45 females with an average age of 47.1 years (range 18-70 years). The duration of symptoms ranged between 3 and 22 months with one of studies, Owens (2011), reporting that all subjects had at least 6 months duration of symptoms [25]. There were eight patients with calcaneal insertional Achilles tendinopathy and 22 with non-insertional Achilles tendon disease in Monto's study [13]. The other three studies, Gaweda (2010), Owens (2011), de Vos (2010) assessed non insertional Achilles tendinopathy located more than $2 \mathrm{~cm}$ above the tendon insertion. In the RCT, de Vos (2010) [24], the diagnosis was made based on clinical findings: all patients had a painful and thickened tendon (on palpation and in relation to activity) located 2 to $7 \mathrm{~cm}$ proximal to the insertion on the calcaneus. The other three studies $[12,13,25]$ used radiological findings

\section{Inclusion Criteria}

- Study included achilles tendinopathy only

- Reported the outcome of PRP in achilles tendinopathy. - Study written up in English

Figure 1. Inclusion criteria.

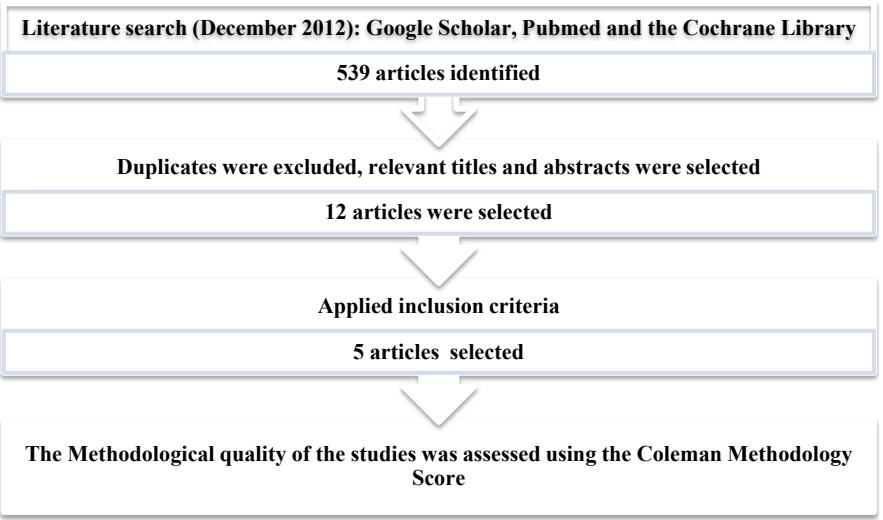

Figure 2. Flowchart of literature review process. 
Table 2. Included Studies.

\begin{tabular}{|c|c|c|c|c|c|c|c|c|c|c|}
\hline Authors & Design & Level & Study Size & $\begin{array}{l}\text { Age } \\
\text { (years) }\end{array}$ & Gender & $\begin{array}{l}\text { Duration of } \\
\text { symptoms }\end{array}$ & Treatment & Advice following PRP & $\begin{array}{l}\text { Follow up / } \\
\text { months }\end{array}$ & Outcomes \\
\hline $\begin{array}{l}\text { De Vos } \\
(24) \\
\text { De Jong } \\
(26)\end{array}$ & $\begin{array}{l}\text { Double } \\
\text { Blind } \\
\text { RCT }\end{array}$ & I & $\mathrm{n}=54$ & $\begin{array}{l}49.5(18- \\
70)\end{array}$ & $26 \mathrm{M} 28 \mathrm{~F}$ & $\begin{array}{l}\text { at least } 2 \\
\text { months } \\
(36 \text { weeks } \\
{[24-78] \text { in the }} \\
\text { PRP group \& } \\
26 \text { weeks } \\
{[16-104] \text { in }} \\
\text { the Placebo } \\
\text { group) }\end{array}$ & $\begin{array}{l}\text { PRP injections } \\
\text { \& eccentric } \\
\text { exercises }(\mathrm{n}=27) \\
\text { vs placebo } \\
\text { injections (saline) } \\
\text { \& eccentric } \\
\text { exercises }(\mathrm{N}=27)\end{array}$ & $\begin{array}{l}\text { During the first } 48 \text { hours, allowed to walk } \\
\text { short distances indoors. During three to } \\
\text { seven days post injection, walks up to } \\
30 \text { min were allowed. After the first week, } \\
\text { the exercise program was started and } \\
\text { consisted } 1 \text { week of stretching exercising } \\
\text { and } 12 \text { week daily eccentric exercises. All } \\
\text { patients were instructed to avoid weight } \\
\text { bearing sporting activities in the first } 4 \\
\text { weeks. After } 4 \text { weeks a gradual return to } \\
\text { sporting activities was encouraged }\end{array}$ & 12 & $\begin{array}{l}\text { VISA Improvement } \\
\text { in Pain \& Function } \\
\text { but no differences } \\
\text { between the two } \\
\text { groups }\end{array}$ \\
\hline $\begin{array}{l}\text { Gaweda } \\
\text { (12) }\end{array}$ & $\begin{array}{l}\text { Case } \\
\text { Series }\end{array}$ & IV & $\begin{array}{l}\mathrm{n}=14(15 \\
\text { tendons })\end{array}$ & $\begin{array}{l}40(24 \\
-52)\end{array}$ & $\begin{array}{l}8 \mathrm{M} \\
8 \mathrm{~F}\end{array}$ & $\begin{array}{l}6 \text { months (3 } \\
-10)\end{array}$ & PRP injections & $\begin{array}{l}\text { First } 3 \text { days - non weight bearing. In the } \\
\text { next two weeks used walking crutches } \\
\text { with pressure applied to anterior section } \\
\text { of foot + passive exercises to ankle joint. } \\
\text { Subsequent two weeks load on foot was } \\
\text { increased using heel lift with passive } \\
\& \text { active exercises. Full load without } \\
\text { crutches commenced } 6 \text { weeks post } \\
\text { injection }\end{array}$ & 18 & $\begin{array}{l}\text { Improved AOFAS, } \\
\text { and VISA, and } \\
\text { Echotexture }\end{array}$ \\
\hline $\begin{array}{l}\text { Monto } \\
\text { (13) }\end{array}$ & $\begin{array}{l}\text { Case } \\
\text { Series }\end{array}$ & IV & $\mathrm{n}=30$ & $\begin{array}{l}47(36- \\
66)\end{array}$ & $17 \mathrm{M} 13 \mathrm{~F}$ & $\begin{array}{l}8 \text { months } \\
(6-22)\end{array}$ & PRP injections & $\begin{array}{l}\text { Placed into a CAM walker brace for } 48 \\
\text { hours. Then allowed to return to activities } \\
\text { as tolerated with home eccentric exercise } \\
\text { programme. NSAID use was not permitted } \\
\text { in first } 2 \text { weeks and was discouraged } \\
\text { throughout study period. }\end{array}$ & 24 & $\begin{array}{l}\text { Improved AOFAS. } \\
\text { MRI \& US } \\
\text { abnormalities } \\
\text { improved in } 27 \text { out } \\
\text { of } 29 \text { patients }\end{array}$ \\
\hline $\begin{array}{l}\text { Owens } \\
(25)\end{array}$ & $\begin{array}{l}\text { Case } \\
\text { Series }\end{array}$ & IV & $\begin{array}{l}\mathrm{n}=10(11 \\
\text { tendons }\end{array}$ & $\begin{array}{l}52.1(41- \\
52)\end{array}$ & $\begin{array}{l}2 \mathrm{M} \\
8 \mathrm{~F}\end{array}$ & $\begin{array}{l}\text { at least } 6 \\
\text { months }\end{array}$ & PRP injections & $\begin{array}{l}\text { Patients were immobilised in a walking } \\
\text { boot for } 4 \text { weeks. Then gradually resumed } \\
\text { activity. Physiotherapy was not ordered } \\
\text { post injection. }\end{array}$ & $\begin{array}{l}\text { Mean } 13.9(7.8 \\
-23.4)\end{array}$ & $\begin{array}{l}\text { Improved SF-8, } \\
\text { FAAM and FAAMS } \\
\text { scores. One in } 6 \\
\text { Achilles tendons } \\
\text { demonstrated MRI } \\
\text { improvement }\end{array}$ \\
\hline
\end{tabular}

to confirm the diagnosis. As seen in table 3, the majority of the studies had significant methodological limitations, as reflected by the mean CMS of 52 (range $33-68$ ).

In Gaweda's study [12] failure of other treatment modalities included plaster cast immobilisation in eight subjects, physiotherapy in ten subjects and steroid injections in four subjects. In Monto's study [13], patients had failed a minimum 6- month trial of standard nonoperative treatment including rest, physical therapy, silicone heel lifts, Controlled ankle motion (CAM) walker bracing, cast immobilization, night splinting, and non-steroidal medication. All patients in the study were required to have spent a minimum of 8 (range, 8 to 13) weeks in a CAM-walker boot. Owens [25] specifies that all patients had physical therapy prior to treatment and all patients had at least 6 months symptom duration. In the RCT, de Vos (2010) [24], subjects were excluded if they had previously completed a heavy load eccentric exercise programme and other treatment modalities prior to injection were not specified.

In a prospective cohort study, Monto (2012), 30 patients were treated with a single ultrasound guided diamond shaped injection pattern of PRP. The American Orthopaedic Foot \& Ankle Society [AOFAS] Ankle-Hindfoot Score was concluded for all patients prior to PRP injection and at $0,1,2,3,6,12$, and 24 months post-treatment. Repeat MRI or ultrasound imaging studies were completed on all patients and compared to the pretreatment findings. The average AOFAS score increased from an average baseline of 34 (range 20-60) to 92 (range 87-100) by 3 months after PRP treatment and remained elevated at 88 (range 76-100) at 24 months. The imaging abnormalities (achilles swelling, calcifications and partial tears) present in the Achilles tendon resolved in 27 of 29 patients. In 27 of 30 patients, 9 were able to return to their former occupations and 9 returned to their sport. The strengths of this study are its prospective longitudinal nature, the length of follow up, and its high subject retention rate. The absence of a placebo group is the primary weakness of this study. Despite the treatment success seen in this study, the patients proved to be noncompliant with postoperative care. They were instructed to use the CAM walker for 48 hours and refrain from NSAID use, but this was unmonitored. All patients in this study were also instructed in a home based eccentric exercise program but the majority of patients performed their exercises sporadically. A supervised programme may be more effective to ensure compliance. It is uncertain what role unrecorded postoperative NSAID use might have had on the clinical results. Another potential problem with this study is its reliance on the AOFAS hindfoot scoring system to differentiate clinical performance. Although another scoring system might have been preferable, this was the system chosen and used in this prospective study. The AOFAS system has difficulty with assessing patient satisfaction and activity levels. This is evident in this study where both treatment failures displayed fairly high AOFAS scores because of activity restrictions and one lower scoring patient (AOFAS score 76) was quite satisfied with their clinical result. Although both treatment failures in this study were cases with calcaneal Achilles disease involvement, no statistical difference was noted between insertional and non-insertional group results overall [13].

Gaweda used the AOFAS scale for the hind foot, and the Victorian Institute of Sport Assessment - Achilles (VISA-A) scale to evaluate the subjects with Achilles tendinopathy. Ultrasonography (US) and Power-Doppler ultrasonography (PDUS) were used to evaluate tendon homogeneity disruption and vascularity respectively. Physical examination and imaging studies were repeated at 6 weeks, and at 3 , 6 , and 18 months after a $3 \mathrm{ml}$ PRP injection. Six cases with persistent symptoms and tendon degeneration on US had the injection repeated. 
During follow up, a significant improvement was observed in the clinical and imaging results [13]. Similar to Monto's study [13] there was an improvement in the AOFAS scale from a baseline of 55 (range $36-72$ ) to 96 (range $82-100$ ) at 18 months ( $\mathrm{p}=0.000655$ ), The VISA-A scale also improved from a baseline of 24 (range 8 -31) to 96 (range 80 - 100) $(\mathrm{p}=0.000655)$ in the final assessments. PDUS microcirculation signals in the tendon body were absent in 13 cases at 18 months and US assessment showed a decreased tendon and peritendineum thickening in the area of intrasubstance tears, and resolution of hypoechogenic areas. During the final evaluations, two subjects experienced minor pain following activity. The lack of a control group in the above two studies $[12,13]$ may have resulted in a Hawthorne effect, whereby participants might perceive greater benefits associated with an intervention linked to positive outcomes. However, with the elimination of clinical symptoms and the improvement of imaging results, the studies $[12,13]$ provided preliminary evidence that PRP might be an effective treatment in Achilles tendinopathy.

In the double blind RCT, De Vos et al. stratified subjects according to the injury activity levels and patients either received saline or PRP injection $(4 \mathrm{ml})$ followed by a 1 week of stretching exercises and a 12 week eccentric exercise programme. The blinded fluid was injected through three different puncture locations under US guidance. As seen in figure 2, the mean VISA-A score improved significantly within the PRP group by 21.7 points (95\% confidence interval [CI], 13.0-30.5). However once adjusted for baseline VISA scores and duration of symptoms, there was no difference between the treatment groups at 6 , 12 and 24 weeks [24].

Although the PRP and placebo groups showed a clinical progression over the 12 months, the authors felt that this was likely to be resulting from the eccentric exercises. A previous study has demonstrated that the placebo response to an invasive intervention could be amplified and therefore raises high expectations (10). A healing response could also have been initiated by needle trauma or local bleeding $(10,24)$. De Jong et al. extended the above study to a follow up at 1 year. There were no clinical or US benefits of a PRP injection. These results were in line with the findings after 6 months [26].

In contrast to the previous studies, the high quality Level I RCT study had a sample size calculation to ensure appropriate power. There was complete follow up at 1 year with no patients lost and no missing data. The limitation was that the subjects were a self-selected group, who sought active participation in the study, along with the absence of US confirmed tendinopathy. The study only examined patients with early Achilles disease and mild to moderate symptoms who had not been previously treated. A non-injected control group was not included. Although all patients in the PRP and placebo groups improved over the course of 12 months, twice as many patients in the PRP group returned to sporting activities than in the placebo group at 6 months follow up. Since the population studied was sub-optimal, it limits the external validity and ability to generalize results in patients with Achilles tendinopathy. Ideally the selected population would have been subjects who had failed a standard eccentric program [13].

Owens et al's [25] retrospective study included 10 patients (11 tendons) treated for chronic midsubstance Achilles tendinopathy with PRP injection over a 2-year period. Baseline and post injection functional scores including the Foot and Ankle Ability Measure (FAAM), Foot and Ankle Ability Measure - Sports (FAAMS), and the Short Form health survey (SF-8) were assessed. MRI images pre- and post- PRP were compared. This process contrasted to the other three studies $[12,13,24]$ mentioned above, as modest improvements were found in the outcome.. Average SF-8 scores improved from 24.9 to 30.0 on a 40 -point scale $(p=0.06)$. FAAM scores improved from an average of 55.4 to 65.8 on an 84-point scale $(p=0.16)$ and FAAM-S scores improved from 14.8 to 17.4 on a 32 -point scale $(p=0.46)$. Clinically all the patients, except one, reported improvement in their symptoms however, only one in six Achilles tendons demonstrated qualitative MRI improvement post-injection. It is possible that the mere act of injecting a volume of fluid into the tendon achieves some degree of pain relief, as shown by de Vos et al. [24], when they compared PRP to saline injection. A downside to this was the lack of physical therapy input post injection, as additional benefit could have been achieved. [25]

\section{Discussion}

Our increasing knowledge, understanding and preliminary evidence from experimental data that GFs, present in plasma, boosts tendon repair mechanisms through recruitment, proliferation and differentiation of cells, has driven the use of PRP preparations in the treatment of Achilles tendinopathy [27]. However, the role and clinical effectiveness of PRP use in Achilles tendinopathy is at its infancy.

Abate [28] outlines several theoretical and practical reasons about the possible cause of treatment failure. Animal studies are carried out on "surgically induced" tendons, so it is debatable whether these models mimic human pathology, where human tears usually occur in degenerated tendons. The pathway of chronic tendinopathies is very complex, involving many pathogenetic factors, including GFs, which operate at different stages of the disease [28].

Although all four studies [12,13,24,25] used leucocyte and PRP, different methods have been used to produce the PRP, which can result in a large variation in GF content, and in the kinetics of release [28]. The optimal PRP formulation is unknown, with platelet concentrations differing widely. The concentration of platelets in PRP can range from 2.5 to 8 times the concentration found in whole blood [28]. Moreover different formulations may be required at different stages of tendon healing or for patients with different histopathological or biochemical features [29].

The clinically applicable evidence on the role of PRP in Achilles tendinopathy to date stems mainly from the above four studies. But due to their differing study protocols, comparison of results is difficult. These limitations are recognized by NICE [30], who acknowledge that "current evidence on the safety and efficacy of autologous blood injection for tendinopathy is inadequate in quantity and quality. Therefore this procedure should only be used with special arrangements for clinical governance, consent and audit or research".

There is a variation in the agreed gold standard of diagnosis, where the majority $[12,13,25]$ used ultrasound and/or MRI in combination with physical examinations. An exception is de Vos et al. [24] who confirmed the diagnoses clinically.

The classification of acute and chronic Achilles tendinopathy is unclear, with a variable mean duration of symptoms prior to enrolment in the studies. In the RCT, de Vos included symptomatic subjects for at least 2 months [24], whilst Owens included subjects with at least 6 months of symptoms [25]. Additionally, the degenerate tendon pathology seen in Achilles tendonopathy may not be responsive to PRP injections [28]. This makes it difficult to compare the studies and further research is needed.

The four authors [12,13,24,25] utilised US guided injections to accurately deliver the PRP into the pathologic tendon. Monto used 
a diamond-patterned injection array technique to achieve a broader zone of delivery [13]. Another controversy remains; regarding the optimal volume, number, and interval of injections. Volumes ranged between $2 \mathrm{ml}$ to $6 \mathrm{ml}$ per injection. PRP generally requires a single injection however in Gaweda's study [12] the six cases with non resolving symptoms and persistent tendon degeneration on US had the injection repeated. No study comparing dry needling alone to PRP has, to our knowledge, been performed. The protocols and advice following the PRP injections (immobilisation vs. physiotherapy vs. nil formal) varied and may have confounded results. Although not all studies have utilised physiotherapy, especially eccentric loading exercises, post blood injections, these exercises are likely to play a role during the remodelling stages of tendon repair [31]. The duration of follow up also varied between studies.

In conclusion, early results regarding the use of PRP in Achilles tendinopathy, especially in refractory cases unresponsive to traditional treatment modalities, look promising. However these are based on small clinical studies. While these early findings are clearly of considerable interest to athletes and the general population, long term well-conducted studies, are needed to further clarify the role of PRP and its potential efficacy and whether it provides advantages to more traditional treatment modalities in Achilles tendinopathy [10]. It is necessary to standardize PRP preparation, and to establish the modalities of its activation and administration. Finally, new strategies in PRP use should be exploited: among them, the association of PRP with autologous stem cells or the administration of selective GFs (PDGF, VEGF, or anti-angiogenic factors), which could be better options in specific situations $[28,29]$. Future studies should also continue to address and demonstrate the safety of PRP in human applications [10].

\section{References}

1. Maffulli N, Wong J, Almekinders LC (2003) Types and epidemiology of tendinopathy. Clin Sports Med 22: 675-692. [Crossref]

2. Khan KM, Maffulli N (1998) Tendinopathy: an Achilles' heel for athletes and clinicians. Clin J Sport Med 8: 151-154. [Crossref]

3. Järvinen M(1992) Epidemiology of tendon injuries in sports. Clin Sports Med 11: 493 504. [Crossref]

4. Schepsis AA, Jones H, Haas AL (2002) Achilles tendon disorders in athletes. Am J Sports Med 30: 287-305. [Crossref]

5. Alfredson H (2003) Chronic midportion Achilles tendinopathy: an update on research and treatment. Clin Sports Med 22: 727-741. [Crossref]

6. Van Linschoten R, den Hoed PT, de Jongh AC (2007). Guideline 'Chronic Achilles tendinopathy, in particular tendinosis, in sportsmen/sportswomen'. Ned Tijdschr Geneeskd 151:2319-24. [Crossref]

7. Woo SLY, Renstrom PAFH (2007) Tendinopathy in Athletes, the Encyclopaedia of Sports Medicine, Vol. XII. Hong Kong: Blackwell Publishing, 1-9.

8. Van Sterkenburg MN, van Dijk CN (2011) Injection treatment for chronic midportion Achilles tendinopathy: do we need that many alternatives? Knee Surgery, Sports Traumatololgy, Arthroscopy 19: 513-515. [Crossref]

9. Kraushaar B, Nirschl RP (1999) Current concepts review: Tendinosis of the elbow (tennis elbow). Clinical features and findings of histological, immunohistochemical, and electron microscopy studies. Journal of Bone and Joint Surgery 81: 259-278.
10. Kampa RJ, Connell DA (2010). Treatment of tendinopathy: is there a role for autologous whole blood and platelet rich plasma injection? Int J Clin Pract 64: 18131823 [Crossref]

11. Astrom, M; Rausing, A (1995). Chronic Achilles tendonopathy: A survey of surgical and histopathological findings. Clin Orthop Relat Res 316: 151-164. [Crossref]

12. Gaweda K, Tarczynska M, Krzyzanowski W (2010) Treatment of Achilles tendinopathy with platelet-rich plasma. Int J Sports Med 31: 577-583. [Crossref]

13. Monto RR (2012) Platelet rich plasma treatment for chronic Achilles tendinosis. Foot Ankle Int 33: 379-385. [Crossref]

14. de Vos RJ, van Veldhoven PL, Moen MH, Weir A, Tol JL, Maffulli N (2010) Autologous growth factor injections in chronic tendinopathy: a systematic review. $\mathrm{Br}$ Med Bull 95: 63-77. [Crossref]

15. Paavola M, Kannus P, Paakkala T, Pasanen M, Järvinen M (2000) Long-term prognosis of patients with achilles tendinopathy. An observational 8-year follow-up study. Am J Sports Med 28: 634-642. [Crossref]

16. Velnar T, Bailey T, Smrkolj V (2009) The wound healing process: an overview of the cellular and molecular mechanisms. J Int Med Res 37: 1528-1542. [Crossref]

17. Borregaard N, Cowland JB (1997) Granules of the human neutrophilic polymorphonuclear leukocyte. Blood. 89(10):3503-3521. [Crossref]

18. Murphy G, Bretz U, Baggiolini M, Reynolds JJ (1980) The latent collagenase and gelatinase of human polymorphonuclear neutrophil leucocytes. Biochem J 192: 517525. [Crossref]

19. Eppley BL, Woodell JE, Higgins J (2004) Platelet quantification and growth factor analysis from platelet-rich plasma: implications for wound healing. Plast Reconstr Surg 114: 1502-1508. [Crossref]

20. Frechette JP, Martineau I, Gagnon G (2005) Platelet-rich plasmas: growth factor content and roles in wound healing. J Dent Res 84: 434-439. [Crossref]

21. McCarrel T, Fortier LA (2009) Temporal growth factor release from platelet-rich plasma, trehalose lyophilized platelets and bone marrow aspirate and their effect on tendon and ligament gene expression. J Orthop Res 27: 1033-1042. [Crossref]

22. Molloy T, Wang Y, Murrell G (2003) The roles of growth factors in tendon and ligament healing. Sports Med 33: 381-394. [Crossref]

23. Menetrey J, Kasemkijwattana C, Day CS, Bosch P, Vogt M, et al. (2000) Growth factors improve muscle healing in vivo. J Bone Joint Surg $\operatorname{Br}$ 82: 131-137. [Crossref]

24. de Vos RJ, Weir A, van Schie HT, Bierma-Zeinstra SM, Verhaar JA, et al. (2010) Platelet-rich plasma injection for chronic Achilles tendinopathy: a randomized controlled trial. JAMA 303: 144-149. [Crossref]

25. Owens RF Jr, Ginnetti J, Conti SF, Latona C (2011) Clinical and magnetic resonance imaging outcomes following platelet rich plasma injection for chronic midsubstance Achilles tendinopathy. Foot Ankle Int 32: 1032-1039. [Crossref]

26. de Jonge S, de Vos RJ, Weir A, et al (2011) One-year follow-up of platelet-rich plasma treatment in chronic Achilles tendinopathy: a double-blind randomized placebocontrolled trial. Am J Sports Med 39: 1623-16239 [Crossref]

27. Andia I, Sanchez M, Maffulli N (2010) Tendon healing and platelet-rich plasma therapies. Expert Opin Biol Ther 10: 1415-1426. [Crossref]

28. Abate M, Di Gregorio P, Schiavone C, Salini V, Tosi U, et al. (2012) Platelet rich plasma in tendinopathies: how to explain the failure. Int J Immunopathol Pharmacol 25: 325-334. [Crossref]

29. Cole BJ, Seroyer ST, Filardo G, Bajaj S, Fortier LA (2010) Platelet-rich plasma: where are we now and where are we going? Sports Health 2: 203-210. [Crossref]

30. National Institute for Health and Clinical Excellence. Autologous Blood Injection for Tendinopathy: Guidance. http://www.nice.org.uk/nicemedia/pdf/IPG279Guidance. PDF (accessed November 2012)

31. Andres BM, Murrell GA (2008) Treatment of tendinopathy: what works, what does not, and what is on the horizon. Clin Orthop Relat Res 466: 1539-1554. [Crossref]

Copyright: $\odot 2018$ Sammut L.This is an open-access article distributed under the terms of the Creative Commons Attribution License, which permits unrestricted use, distribution, and reproduction in any medium, provided the original author and source are credited. 